\title{
Resiliency Factors: An Exploration of Slovenia and US Women in Higher Education
}

\author{
Vita Jones ${ }^{1, *}$, Dawn Person ${ }^{2}$, Clarissa Leyva ${ }^{3}$ \\ ${ }^{1}$ Department of Special Education, College of Education, California State University Fullerton, United States \\ ${ }^{2}$ Center for Research on Educational Leadership (C-REAL), California State University Fullerton, United States \\ ${ }^{3}$ Department of Psychology, College of Education, California State University Fullerton, United States
}

Received July 24, 2020; Revised September 22, 2020; Accepted October 19, 2020

\section{Cite This Paper in the following Citation Styles}

(a): [1] Vita Jones, Dawn Person, Clarissa Leyva, "Resiliency Factors: An Exploration of Slovenia and US Women in Higher Education," Sociology and Anthropology, Vol. 8, No. 6, pp. 171 - 177, 2020. DOI: 10.13189/sa.2020.080601.

(b): Vita Jones, Dawn Person, Clarissa Leyva (2020). Resiliency Factors: An Exploration of Slovenia and US Women in Higher Education. Sociology and Anthropology, 8(6), 171 - 177. DOI: 10.13189/sa.2020.080601.

Copyright $\bigcirc 2020$ by authors, all rights reserved. Authors agree that this article remains permanently open access under the terms of the Creative Commons Attribution License 4.0 International License

\begin{abstract}
This paper examines factors influencing resilience in United States (US) university women of color and their Slovenian counterparts. Several US professors were invited to Slovenia to present each country's vision for success for women in higher education. In preparation for the conference, two US professors took an investigative approach to draw parallels between the US women of color and the Slovenian students. A systematic analysis of review of literature on Slovenian women was employed to examine the resilience factor for women in higher education. The findings identified three challenges Slovenian women face that included: a) limited support from family members; b) balancing school, work and family; and c) time management. Nine US women of color who were part of a southern California university learning community were also studied using a questionnaire, critical incident review, and interviews to examine the obstacles to educational attainment. Four themes emerged: a) group member conflicts; b) poor communication; c) work-life balance; and d) living away from home. The findings of the studies indicated that living up to expectations, advocating for oneself, recommitting to degree completion, practicing self-care, relinquishing perfectionism, incorporating personal responsibility, and asking for help were resiliency factors contributing to successful degree completion. This article offers insights into the resiliency factors that contribute to women's academic success and upward mobility.
\end{abstract}

Keywords Women, Resiliency Factors, Woman in Higher Education

\section{Factors Influencing Resiliency: Women in Higher Education}

Globally, women experience a hierarchical system that routinely impedes their success. Rational and feminist thought regarding female educational resilience is a part of the current global dialogue. Within feminist theory a critical lens exists to examine the experiences of women of color. More than American women of European descent, women of color often have to overcome additional societal constraints to enroll at and graduate from a university course. The incorporation of resilience factors is an effective process to offset the deleterious effects impacting academic attainment. As women become resilient, they transform not only their own lives but the lives of those around them. Pro-feminist theory explores methods to empower women and support the fulfilment of a positive lifestyle. A component of this framework is the ability to express the female voice and structure through their own narratives. Giving expression of the critical nuances of obtaining a higher education degree affirms the need for resilient characteristics. Through their reflection and activism, women are free to express and resolve the education challenges as well as work-life balance issues that impact their lives. A space where two ideologies merged was an international conference where US and Slovenian women assembled virtually to exchange information on practices leading to upward social and 
academic mobility. This paper examines characteristics of resilience in the US university women of color and their Slovenian counterparts.

\section{University Experiences of US Women of Color and Slovenian Women}

Women of color in US universities who are degree seeking face a host of obstacles. These individuals are often expected to serve as role models, and they frequently report isolating themselves to protect their psyche from well-meaning liberals and institutional, racist practices [1]. This practice is taxing and impedes their ability to move in and out of already hostile spaces. One area of unfair scrutiny is the evaluation performance process created and implemented by white counterparts with a white lens of performance. These and other nuances pose a burden for diversity on the female students of color [2]. People of color make up $40 \%$ of the American population but only $5 \%$ of these individuals are college presidents. Students of color state they do not see themselves represented in the leadership nor do they feel that they have a voice in how they are treated. Students of color often report experiencing a climate of hostility and do not report favorable interactions with professors. Women of color stated they feel obligated to assimilate into the dominant culture, which causes them to often deny their own cultural identity [3]. Furthermore, these women are often over-involved with social justice issues in an attempt to resist the philosophy of the dominant culture. This work is rarely consensual but is taken as a means of finding a space in academia that resonates with their respective culture. Students further report that it is rare for them to see themselves reflected in the faculty or administrative demographic [4].

Additionally, Slovenian women in universities are primarily ethnic Slovenes with an increasing number of immigrants from neighboring areas (i.e. Hungarians and Bosnians). Slovenia has more women in higher education than men. Vocational and academic programs are offered as there is a need for both intelligence and industrialization within the country. Additionally, government funding has made child-care more accessible for women; many of which are students. In the US, higher education is regulated by the Higher Education Act of 1993. Through this initiative, public college schools are free to natives. This is important to note as there are private as well as public institutions. Most degrees awarded are for teaching, and 93\% of teachers are women. United States and Slovenian women obtaining education degrees are faced with many obstacles as neither country's academic system is specifically designed for them. Teachers are primarily women in Slovenian [5]. Therefore, women pursuing higher education degrees become resilient as they adapt, recover, and grow from personal and educational difficulties. The academic patriarchal nuances are ingrained in both systems and have been in existence for many generations. High-paying positions are generally held by men. Educated women translate to educated families and societies which also increases the economic base of a society or group. Additionally, educated women experience less infant mortality and have higher earning potential. US women of color and Slovenian women share the legacy of suffragists; US women of color were granted the right to vote in 1965 and Slovenian women 1990. The salary of women of color in the U.S and Slovenian women are comparatively less than men in same field [6]. In addition, women with access to education generally require tenets of resilience to offset the patriarchal restraints that exist throughout the world.

\section{Methods}

\subsection{Participants}

Using Qualtrics, a survey platform, students were able to receive a formatted questionnaire which consisted of descriptor questions (e.g. age, major, ethnicity). They were also given a questionnaire for the Critical Incident that enabled them to reflect on the challenges they encountered as well as the coping mechanisms they employed. Participants had two weeks to complete the critical incident by responding via Qualtrics. The final item to complete this study was a one-on-one interview where the women were asked to share their experiences as a transfer student and a member of the scholarship program. Students shared academic, social, and familial challenges as well as factors that supported them in overcoming those challenges.

\subsection{Design and Procedure}

The following procedures were conducted by a four-year southern California, student-run research team. The research team has been training student research assistance on quantitative and qualitative research procedures for over ten years. Students have been known for their work, especially for using a critical lens focused on social justice within educational interventions in educational programs evaluated in the southern California region. For this purpose, the students at the university center were requested to conduct research procedures on their campus. Using purposive sampling, the center coordinated with the faculty mentor to schedule in-depth individual interviews with the scholars. In addition to participating in an individual interview, students were required to complete an online demographic questionnaire (e.g. Qualtrics) and a critical incident reflection prior to participating in an interview. To contextualize this study, a systematic review of the literature was conducted on Slovenian women in 
higher education as well as women of color in US higher education.

\subsection{Critical Incident}

Researchers utilized Stephan Brookfield's critical incident questionnaire (CIQ); a formative post-class assessment tool that provides an understanding of how students experience learning and instruction. A critical incident is defined as a short description of vivid events that are remembered as important. The CIQ is an efficient way to discover how an instructor's teaching methods impact students as well as understanding the emotional tenor of the class [7]. The participants $(n=9)$ were asked to describe a difficult incident that occurred during their participation of the program. The questions were posed as:

(a) What happened (i.e. time, place)?

(b) What made the event significant?

(c) How was it handled?

The purpose of a critical incident is to capture the experience of the participants by having them describe a critical moment. Stephen Brookfield developed a Critical Incident questionnaire to identify the mental processes experienced when describing a particular incident. In an effort to analyze the detailed description given to the researchers, researchers identify assumptions within the description and infer the reasons for the action or belief. In doing so, researchers must reflect on the participants' value systems inferred followed by the assumption made which drew the participant to the action made.

\subsection{Individual Interview}

All but one of the individual interviews were conducted in a conference room at the university. Eight of the nine students came in person to be audio recorded using Sony voice recorders. One of the student interviews was conducted via Zoom. Researchers used a crude analysis system of analysis. A crude analysis consists of conceptual themes found throughout the interviews.

\section{Systematic Review of Literature}

The study of Slovenian university women consisted of a systematic review of the literature regarding the trends and perspectives of Slovenian women in education with similar educational goals and aspirations. The information regarding Slovenian women and their educational experiences was gathered from peer-reviewed journal articles, websites, and educational literature. Combined, this design allowed the researchers to explore these two unique populations who share gender as a common variable and higher education as the setting for this study.

\section{Analyses of Data}

Data were analyzed using SPSS for statistical analysis of the survey data focusing primarily on descriptive statistics and frequency of responses. Critical incidents data and interviews were analyzed using Dedoose, a software package for qualitative data, and coded using open coding for emergent themes. The systematic literature review was conducted and analyzed providing a summation of historical trends, reported perceptions of challenges, and resilience factors leading to academic success.

\section{Results}

For Slovenian women, three findings emerged that included: a) limited support from family members; b) the balancing of school, work, and family; and c) well-planned time management. The lives of Slovenian university women were examined for evidence of how they completed their academic trajectory. Slovenians have a Commission on the Status of Women (CSW) organization. The commission is tasked with examining data on the state of women throughout the world and informs societal agencies of procedural changes to address issues such as the work-life balance and education of women. The collaboration of committees within the CSW advocate for policy changes in educational, societal, and political systems. The counsel of CSW note that women are overwhelmingly underrepresented in high economic positions and carry the major responsibilities for home and domestic life, which contribute to an unsustainable workload. The commission forms task forces to investigate the impact of men's higher social, political, and economic status on women's work-life balance. In regions where studies have been conducted, $75 \%$ of societies are male dominated and women are relegated to a lesser role in decision making and economic earnings.

Through the development of the Institute for Labour Law at the Faculty of Law (IDPF) at the University of Ljubljana, women actively engage in spirited discussions of current issues pertaining to their educational trajectory. A process of collective agreements is also being formed to address limits on overtime work, family friendly working hours, child care and pay differentials, and increased father involvement. Out of those surveyed, ninety-three percent of Slovenian citizens agreed that work and education attainment for women is a national crisis. The educational attainment of women in Slovenian is increasing with over $40 \%$ of women attending institutions of higher education for the past two decades. As a rule, the decision to attend university impacts the decision to marry and have a family. It is common for young women to forfeit moving away from home and marrying to attend college. This extends the students' dependence on their families [8]. 


\subsection{Family Support, Balancing School, Work and Family, and Time Management}

Slovenian women report a high satisfaction with family life. Furthermore, they make up $45 \%$ of the work force-over sixty percent of which are employed in the agricultural field. Traditional roles are still considered a priority for Slovenian women as primary home duties are still performed by them. The domestic unit consists of marriage partners and children and often elder family members. The family relationship is enhanced by spiritual influences. Women are employed in primarily three roles: cultural and social, public services and administration, and the hospital field. Women were granted limited civic and political authority after World War II. However, kin groups called zadruga owned property before the twentieth century contributing to the resilience of women in the country. In general, over $30 \%$ of Slovenians earn postsecondary or higher levels of degrees. There are higher learning institutions and two universities. It is popular to earn a "first stage" degree which is similar to an associate two-year degree [9].

Nine US women who were part of a learning community were surveyed and interviewed to uncover their resilience factors. Four categorical themes were identified: a) group member conflicts; b) poor communication; c) work-life balance; and d) living away from home. Group conflict resolution arose as students collaborated to complete the campus project. Participants noted personal conflict within the group as they worked closely together and set boundaries with other cohorts to diminish negative interactions. Participants cited different work styles, not being appreciated for their contributions, and a lack of communication as a challenge in maintaining work-life balance. Students were challenged by life transitions such as moving away from home, becoming financially independent, and living with each other. Finally, participants often expressed the concept of family pressure in completing their program as a first-generation student. To address the themes noted in the study, US students identified the following through the critical incidence data:

a) Living up to expectations. One student whose mother had passed away recounted, "my mom would want me to do it".

b) Advocating for oneself. Another student stated, "I discussed my challenges with peers to get advice."

c) Recommitting to degree completion. A student said they were recommitted because they were, "[the first] college graduate in the family."

d) Practicing self-care. This was explained by a student saying, "I am really into self-care.... I get messages every month, I get facials.... I like to do things to make me feel good."

e) Relinquishing perfectionism was described by a student who had a disability with the following statement: "Since I found out about my learning disability, I noticed [that music] is the number one thing that helps me concentrate and helps me keep calm."

f) Incorporating personal responsibility. One student noted that, "I had to stop partying and take school serious."

g) Asking for help, to which a student commented, "I learned to ask for help."

Students recounted practices of self-care such as meditation, reading the bible, and going to church. Also, several students discussed the importance of being flexible and taking note of the growth in their lives. Personal responsibility rated high as students progressed through the program and incorporated more of this skill in their senior year as opposed to the junior year. Finally, all of the students reported that utilizing the campus resources provided essential support for staying engaged in the educational process. A student commented that she, "put herself in check," when she felt like giving up on college.

Through the use of the critical incident data collection process, the nine women reported problems they encountered during their first and second semester of college after transferring to the university. These problems included academic issues such as low performance in classes, emergence of learning disabilities, and overall stress. Most of the women experienced the stress of living in the university residence facilities away from family. As a result of these stressors, some women reported mental health issues. Undergirding all of this were feelings of low self-esteem and a limited sense of belonging in the college and the program. These issues left many of the students unable to complete tasks in a timely manner. Given these challenges, the women reported feelings of loneliness, depression, irresponsibility, loss, and a disconnection with the familiar and their peers. There were times when they felt psychologically unsafe and unsupported by the group. At times, some felt they no longer belonged in school or the program. The women described action steps they took to combat these challenges and negative feelings. These actions required them to consult with their program mentor and she referred them to campus services such as counseling (psychologist and psychiatrist) and health services. Friends, family, and affinity groups provided needed support. A few of the women found solace in their church community while others turned to their previous educational support system.

When the women were asked to describe their points of resilience, they commented on their desire to make supporters proud and share their experiences with others. One student said, "self-care and self-advocacy were critical." Almost all the participants said they would take better care of themselves and re-commit to completing their degree. The development of a stronger sense of self in terms of advocacy, reliance, and responsibility was manifested in their responses to challenges over time. They learned to let go of both perfectionism and the imposter syndrome. Allowing themselves to matter and hold on to 
their dreams and educational aspirations was crucial to their success. One student shared, "I know I was meant for much more in this life."

Table 1 provides an overview of the four themes that emerged from the data on the nine US women in the university. Each theme is presented in the chart and described in more detail with quotes to support each theme.

Table 1. Emergent themes: US woman cohort experience

\begin{tabular}{|l|l|}
\hline Theme & Description \\
\hline $\begin{array}{l}\text { Conflict resolution skills gained } \\
\text { as a result of group conflict. }\end{array}$ & $\begin{array}{l}\text { "Working amongst other } \\
\text { woman served as a learning } \\
\text { experience for conflict } \\
\text { resolution skills." }\end{array}$ \\
\hline $\begin{array}{l}\text { Personal conflict within the } \\
\text { cohort created individual } \\
\text { learning experiences. }\end{array}$ & $\begin{array}{l}\text { "Scholars used personal } \\
\text { conflict within relationships in } \\
\text { the cohort to promote personal } \\
\text { growth." }\end{array}$ \\
\hline $\begin{array}{l}\text { Internal conflict due to life } \\
\text { transitions promoted } \\
\text { interdependence within the } \\
\text { campus community. }\end{array}$ & $\begin{array}{l}\text { "Students describe their } \\
\text { experience moving away from } \\
\text { home, becoming financially } \\
\text { independent, and transferring } \\
\text { froma community college." }\end{array}$ \\
\hline $\begin{array}{l}\text { Family expectations and } \\
\text { stressors served as motivation } \\
\text { for resilience in scholars. }\end{array}$ & $\begin{array}{l}\text { "Students explain their ability } \\
\text { to keep moving forward and } \\
\text { going against culture } \\
\text { expectations of women while } \\
\text { in education." }\end{array}$ \\
\hline
\end{tabular}

\subsection{Conflict Resolution}

During the course of the cohort program, the participants experienced conflict while working with other cohorts. This cohort program was designed to focus on conducting a campus project. In preparation for implementing the campus project, students went from collegial communication to negative social encounters. A cohort said, "I thought it was easier to work with women, but it was actually a challenge... we take things much more personally and we are very dedicated to our work." As leadership roles were assigned several scholars relayed their intimidation of other group members in the cohort. Two of the nine scholars stated that they felt their contribution to the work was not valid or important. However, a majority issue within the group projects was due to a lack of communication among one another. As a result, a student shared, "You would walk into the room and there would be tension to the point you wouldn't want to attend the meetings." Personal feelings outside of the work were taken into consideration and the scholars felt it hindered some of the members' work ethic when it came to the project.

Due to the conflict, the faculty mentor had to step in to provide support with regard to conflict-resolution skills. A student shared, "She changed the layout of our meetings." Given the efforts of the faculty mentor, many of the students completed the program feeling competent in their ability to resolve issues working among women. A student stated, "[It] shaped me in the way of how I deal with conflict... being able to push through while surrounded by powerful mentors and women who also have strong personalities." Although the process of creating an impactful project among each other, many scholars stated that they had changed as a result. Each found their own strengths in approaching one another in regard to an issue. Some in a more direct manner, while others utilized a compassionate approach. One student said, "I value everyone's opinion and believe everyone should be heard." Overall, many of the students appreciated the experience working among one another, and believed they gained perspective on the different leadership styles of women.

\subsection{Personal Conflict}

The students also developed interpersonal conflicts during the course of creating an impactful project. In an individual interview, a student emphasized, "boundaries of professionalism and fun were clouded". The scholars went to school, worked, and lived among one another which led to personal conflict that created a toxic work environment. Leading on from this, one student stated, "I was having anxiety attacks when I shouldn't have, academically I am successful, in work I am successful. It was just the social aspect of [the program] that became stressful to me." The conflict would carry over into different spaces that caused discomfort for some students. Since students sought out each other in their new environment, venting became an issue. As a result, some of the scholars took it upon themselves to set appropriate boundaries. One student said, "I went away from the people who have that negative energy and I went toward the people who actually wanted me to be successful.

\subsection{Internal Conflict}

During the program, students faced multiple life transitions: moving away from home, becoming financially independent, and transferring to a four-year institution. "Moving away and having a new support system was very hard for me," one student said, "which is why I fell to academic probation." Many of the students felt homesick as they had to adjust to a new environment away from their original support systems. This transition to independence began to affect scholars academically. In addition to moving away from home, transitioning from a two-year institution to a four-year institution resulted in transfer shock. A scholar shared, "I felt like the rooms were big and the teachers were detached." Many students' grades began to decline, which led to one scholar discovering she had a learning disability. One student also reported that she suffered from mental health issues, and that it was a prevalent challenge that co-occurred with many significant life transitions. Presented with a different environment, the woman sought out resources to help get them through these 
significant challenges.

A majority of the students relied on their faculty mentor. A student stated that, "[The faculty mentor] did everything in her power to connect me to the right resources; she connected me to the counselor." While many of the scholars resorted to their internal support structures, many of them navigated through their obstacles and were able to create a support system within their cohort. A student said, "I am very family oriented and used to being with family; I cultivate a family within [the program]."

\subsection{Family Expectations}

A majority of the scholars reported that they felt the pressure of succeeding due to their role in their family as first-generation college students. For example, one student said, "Since I am first generation, my family didn't really understand." Being in academia for some students meant going against family customs. Few scholars were given the responsibility of supporting their family financially, but still sought out an education despite their family needs. Leading on from this, one student added, "just because I come from a Mexican family doesn't mean I should follow the traditional woman role, maybe I should break the stereotype that women belong in the kitchen or women take after the men." Many of the students were motivated to be in the program to help build a community of women since the expectation of a woman's role was different from the life they sought for themselves. A student corroborated this by saying, “[I] don't want to be a stereotype or another statistic; I want to help my community and to be a role model to my nieces and my sister." As a result of taking an alternate route and choosing education, some members felt detached from their community and family. However, although separated, the majority of the scholars strived to pursue their education so as to fulfill their role as a model for younger generations. Lastly, both groups experienced familial pressure to complete their degrees.

All of these women demonstrated resilience factors such as recommitting to degree completion, incorporating personal responsibility, and seeking needed assistance. Other aspects were self-advocacy, self-care, living up to expectations, and relinquishing perfectionism. Regardless of geographical spaces, women new to academia found their voices through self-advocacy while never losing sight of the value of education

\section{Implications}

Women in both the US and Slovenia require external and internal factors of resiliency to successfully navigate the university setting. Universally, women are committed to attaining higher education. Women entering institutions of higher education face challenges of accessible education coupled with support systems that lead to degree completion. College resources and family support are essential for women to enter and graduate from college. While the women represent two different sets of cultures, political affiliations, age ranges, and family compositions, they share common resilience factors such as family support and work-life balance persistence. The nine participants in the US cohort study recount the importance of proper mentoring, inter and intrapersonal skills, and learning to advocate for themselves as did their Slovenian counterparts. Both groups of women were developing methods to support their educational journey.

\section{Discussion}

The findings suggest that participants incorporated several factors of resilience in navigating the college system. The literature indicated that all the women benefit from tactics of overcoming difficulties, such as reaching out to others, focusing on self-care, embracing empowerment strategies in an attempt to build resilience, and complete their education. The findings also indicate there are parallels between the Slovenian and US women in obtaining a higher education degree. The resilience characteristics include self-care, self-advocacy, relinquishing perfectionism, and living up to other expectations. This list of characteristics confirms existing theories that women experience unique challenges when pursuing a higher education degree. While these demographics represent two countries it is worth investigating other populations to gain a universal perspective. US students report taking personal responsibility for finding adaptive coping skills to support them. These include spirituality, education, personal accountability. The Slovenian women also reported the impact of spiritual influences in building resiliency. Both groups of women listed the familial pressure and support as motivation for success.

\section{Conclusions}

In this study, we examined the factors influencing resiliency from a universal perspective of two countries. We probed the lives of nine US women of color attending college with a series of demographic questions, a critical incident response, and an interview to determine what they considered to be challenges in navigating university and how they overcame them. Through a descriptive design, we examined the characteristics of resilience identified by two groups of women during their college years; one from the US and the other from Slovenia. Over half of the Slovenian women now have a university degree and are actively involved in a restructuring process to support equal access to learning institutions.

After analyzing the findings, it was noted that the women incorporated seven factors of resilience to 
complete their university education. Previous findings from US and Slovenian studies indicate that although men have a societal advantage when compared to women, women are aware of these inequities and are rising to the challenge of addressing these situations and designing a plan to reach their educational goals. Further noted were the participants' responses to advocate for support and mentoring to continue the process of completing school. Moreover, the US cohort and Slovenian counterparts relayed the importance of family connections for work-life balance and completion of school. Additionally, Slovenian women raised a collective voice for increased partner support in managing domestic obligations whereas the US participants cited peer support as vital in completing school.

\section{REFERENCES}

[1] S. G. Cook. Presumed incompetent: Women of color on campus, Women in Higher Education, Vol. 22, No. 5, 22-22. https://doi.org/10.1002/whe.10436

[2] C. Linder, K. L. Rodriguez. Learning from the experiences of self-identified women of color activists. Journal of College Student Development, Vol. 53, No. 3, 383-398. https://doi.org/10.1353/csd.2012.0048

[3] A. Bonomi. Is higher ed hostile to women of color? The Hispanic Outlook in Higher Education, Vol. 30, No. 11, 18 19.

[4] S. Nair. Women of color faculty and the "burden" of diversity, International Feminist Journal of Politics, Vol. 16, No. 3, 497-500. https://doi.org/10.1080/14616742.2014.92 9357

[5] Eurostat, Women Teachers are Largely Over-Represented in Primary Education in the EU. Online available from https://ec.europa.eu/eurostat/documents/2995521/7672738/ 3-04102016-BP-EN.pdf

[6] Eurostat statistics explained https://ec.europa.eu/eurostat/sta tistics-explained/index.php/Gender_pay_gap_statistics

[7] R. W. Schwester. Handbook of Critical Incident Analysis, M. E. Sharpe, Armonk, 2012.

[8] S. Lutjens. In celebration of politically committed academics, International Feminist Journal of Politics, Vol. 16, No. 3, 501-504. http://dx.doi.org/10.1080/14616742.20 14.929356

[9] Countries and their Cultures https://www.everyculture.com/ $\mathrm{Sa}-\mathrm{Th} /$ Slovenia.html 